\title{
High Schools and University Female Students Knowledge and Attitudes towards Medication Use during Exams in Taif City, Saudi Arabia
}

Badraddin M. Al-Hadiya ${ }^{1 *}$, Majed M. AlRobaian ${ }^{2}$, Kholoud M. Alzahrani ${ }^{3}$, Arwa S. Altalhi ${ }^{3}$, Nada A. Albradi ${ }^{3}$, Afrah F. Alzahrani $^{3}$, Elham A. alsherbi ${ }^{3}$

${ }^{1}$ Faculty of Pharmacy, Al-Neelain University, Khartoum, Sudan

${ }^{2}$ College of Pharmacy, Taif University, P.O. Box: 888, Al-Haweiah, Taif 21974, Kingdom of Saudi Arabia

${ }^{3}$ Pharm D student, College of Pharmacy, Taif University, KSA

DOI: $10.36348 /$ sjmps.2020.v06i09.002

| Received: 05.09.2020 | Accepted: 14.09.2020 | Published: 19.09.2020

*Corresponding author: Badraddin M. H. Al-Hadiya

\section{Abstract}

Self-Medication is an important phenomenon worldwide. In addition to its advantages, it is associated with some risk when medicines are misused or abused. Students may not have the sufficient knowledge about medications that is why the resultant side effects can be very serious. The study mainly aims to evaluate the knowledge and attitudes of high school and university female students (Taif City, KSA) towards the use of medicines during Exams. A self-administered as well as an electronic questionnaire was used to collect responses from the students in March 2017. Total of 363 students were randomly selected and from the university and four high schools and recruited in the study. Respondents recruited with face-to-face questionnaires were 241 (66.4\%), compared to 122 (33.6\%) included electronically. The statistical package for Social Science (SPSS) version 22 was used to analyze the study data. The study showed that about $48.5 \%$ of the female students agreed that exams affect their health status and food habits to a large extent and about $56 \%$ suffer from anxiety during exams. The most prominent health problem during exams was headache (44.3\%) followed by stomach pain $(27.8 \%)$ and respiratory problems (15.9\%). Few students $(15 \%)$ agreed that using medicines would improve their performance, while $(31.4 \%)$ answered that side effects of medication negatively affected their academic performance. The most common drugs used by students during exams period were antihistamine (49\%), followed by painkillers (8\%), and antibiotics and medicines for chest illness $(6.3 \%)$. There is a high prevalence of irresponsible selfmedication among high school and university students, with observed side effects. There is a need to raise the students' awareness about medicines at school, university and homes.

Keywords: Medication, Knowledge, Attitude, During Exams, Female Students, Taif.

Copyright @ 2020: This is an open-access article distributed under the terms of the Creative Commons Attribution license which permits unrestricted use, distribution, and reproduction in any medium for non-commercial use (NonCommercial, or CC-BY-NC) provided the original author and source are credited.

\section{INTRODUCTION}

Medication is any chemical substance, which may be natural or synthetic that has a medical or pharmacological effect on the body [1]. Medication is taken into or placed on the body to: cure a disease, treat a medical condition, relieve symptoms, and/or prevent diseases [2]. As a result of these beneficial effects, medication use has increased recently. All drugs have benefits as well as risks, so with the expansion of medication use and pharmaceutical industry, there is also an increase in hazards, error and adverse events associated with their use [3].

Medication use and safety is now a global issue. Generally there is increased use of prescription, non-prescription, over the counters (OTCs), and traditional-medicines especially among college-students
[4]. A feeling of being overwhelmed with multiple tests can cause students to try to find different relaxation outlets. Sometimes, students turn to drugs use to reduce stress levels. These unhealthy habits lead to more issues down the road, including the risk of addiction and all of the common problems associated with substance abuse [5]. Cardiovascular disease, stroke, cancer, hepatitis, and lung disease can all be affected by drug abuse. Some of these effects occur when drugs are used at high doses or after prolonged use; however, some may occur after just one use [6]. Substances like stimulants, antidepressants, OTC and non-OTC analgesics, antihistamines and some traditional and alternative medicines like Ginko Bilbao are all substances commonly abused by students, in general and during exams [7]. Most Abused Over the counter medication during Exams include Cough product (Dextromethorphan), Cold medicines and/or 
Decongestants (Pseudoephedrine), Laxatives, Analgesics (acetaminophen, NSAIDs and some codeine containing analgesics) and antihistamines. In addition, analgesics and hypnotics are also commonly used by students during exams. It was also reported worldwide that there was increased use of over-the-counter medications by adolescents, including school and university students. Girls tended to self-administer medication more than boys [8-10].

The European School Survey Project on Alcohol and Other Drugs (ESPAD) collected and published comparable data on substance use among 15 to16 year old European students. Key findings from ESPAD 2011 show that: There are only a few countries where the proportion having tried illicit drugs lower in 2011 than was in 1995 [11]. The most prominent case is Ireland, where 37 per cent had tried illicit drugs in 1995, but only 19 per cent had in 2011. Considerable variations between countries about of studies on misuse and consequences of medicines among students during exams were reported worldwide [12-15]. In Riyadh, Saudi Arabia over $80 \%$ of the students reported using NSAIDs for headache and pain relief during exams [16]. Therefore, Health education is important as it builds students' knowledge, skills and positive attitude about students' health-related behaviors [17, 18]. Comprehensive school health programs (CSHP) are that part of school reform that seeks to reduce or eliminate health-related barriers to student academic and personal success. CSHP are designed to reinforce healthpromoting behaviors in students and to provide the skills students need to avoid negative health practices. Therefore, It should be a primary role of the school to teach skills, to impart knowledge and to establish a sound values base in relation to health and drug use to mitigate risk-behaviors which may cause premature mortality and morbidity among our youth. In addition, it could be an example and measure of the success or effectiveness of drug prevention programs [19-23]. Examples of the medicines used by students to improve performance and its efficacy include, stimulants [24-26] and analgesics [27].

This study is the first in Taif city, Kingdom of Saudi Arabia that aims to evaluate university and high schools female students' knowledge and attitudes towards medication use during exams.

\section{Experimental}

This cross-sectional study questionnaire was carried out to determine Female Saudi high schools and university students' knowledge and attitude towards the use of medications during examinations in Taif City, KSA, conducted during the period from October 2016 to March 2017. A self-contained, self-administered questionnaire was distributed in paper and electronic format (face-to-face based and internet-selfadministered based). Data were collected from students at that point of time. A total of 363 female students from Taif University and both government and private high schools in Taif City were invited to participate in the study. The targeted students were randomly selected from rural and urban areas. The questionnaire was originally drafted in English, then translated to Arabic language, and was tested for consistency.

Students eligible for the inclusion in this study were female, age between 15 - 20 years old, for high school students and more than 19 years old for university students. High schools and university students who refused to participate in the study were excluded. The objectives of the study were stated clearly for the participants before commencement of the interview process, as well as in the electronic version of the questionnaire. Verbal informed consent was obtained. The questionnaires were prepared based on the suggestions of Monkey survey program and the World Health Organization on knowledge about medicines among students.

The validity and reliability of the questionnaire was performed by the research female students' team via a pre-tested (face-to-face and on-line survey) pilot sample of 23 high school and university female students, to ensure applicability and to estimate the time frame needed to complete the questionnaire. During the pilot phase respondents were found to understand all the questions without any confusion. Minor suggestions were observed and adopted in the final version. Following a group discussion, the questionnaire was completed. The data from the pilot study was removed from the final analysis.

In both face-to-face and on-line studies convenience sampling method was adopted. It involved proportionate, random sampling to generate the sample size of the participants in this survey study. The sample size was determined according to regular female students in the selected high schools and university at the time of data collection. The average time to conduct the interview was estimated to 20 minutes. Questionnaires were distributed and collected electronically through the social media. Face-to-face interview data was collected manually by female final year Pharm-D students.

A total of 363 students were randomly selected from the university and four schools to achieve the study objectives. The total number of the distributed questionnaires was 363, involving 241 face-to-face questionnaires (118 collected at Taif University and 123 at high schools) and 122 electronic (on-line) from the same area. A twenty nine-item questionnaire was used to attain the study objectives. The questionnaire composed of two parts was developed by the authors after a detailed review of the literature. The two parts were demographics, and knowledge and attitudes (KA) 
questions, and composed of five sections: The first part of the KA represented the knowledge investigation, consisting of 14 questions (Figures 1, 2 and Table 2). The second part was about the attitude of students towards the use of medications during exams (7 questions: Tables $3-7$, Figures 3 -9). The five sections were:-

1) respondent's socio-demographic variables, including educational level, age, nationality, marital status, total number of family members, living area (rural, urban), and if there is any family member working in the health sector.

2) Evaluation or assessment of student's general knowledge on medication use and safety.

3) Focuses on the impact of exams on the health of the student and what are the most health problems which may arise during exams period.

4) This section is the core section of this study, focusing on the attitudes of students towards the use of medications during exams. It has two main questions, one of them with responses (Yes, No, Sometimes) of a question which aims to assess the effect of using medicine on their performance and if they prefer using other alternatives to enhance their performance such as coffee or energy drink. The second question is a direct question about what are the most used medicines during exams and if they experience any side effects.

5) This section is what makes this study more comprehensive by focusing on the roles of parents and schools in modeling the knowledge of the student towards the medicines. It has one (yes /no) question which aims to know if the parents try to educate their daughters about the medication and its side effects, and if the students believed in the importance of the school to raise awareness about medical education.

\section{Data Analysis}

Only completed questionnaires were collected. The current knowledge and attitudes towards medicines use during exams by high schools' and university students in Taif city was moderate. The data were coded, entered, analyzed and digitally stored with the aid of Microsoft Excel. Descriptive statistics were used to describe demographic characteristics of the respondents and other variables. Statistical significance was set at $\mathrm{P} \leq 0.05$. The software statistical package of social science (21.0 SPSS Inc., Chicago III, USA) was used to analyze the study data.

\section{Study approval}

The study approval was first obtained from the College of Pharmacy, Taif University. Ethical approval for the conduction of the research was obtained from the Pharmacy Practice Research Unit (PPRU) Committee, College of Pharmacy, Taif University, Saudi Arabia.

\section{RESULTS AND DISCUSSION}

The questionnaire was distributed to 363 female students; a total of 334 filled questionnaires were collected from the students, making an overall response rate of $92.0 \%$.

\section{Respondents' Demographic characteristics}

Demographic profiles of respondents are summarized in Table (1). High school students' to university students' responses were $172(51.5 \%)$ and $162(48.5 \%)$, respectively. The students' age ranged from 16 to 26 years. The majority of the female students were Saudi nationals $(302,90.4 \%)$. Only 41 $(12.3 \%)$ of the students were married and $20(6 \%)$ came from rural areas (Table 1).

\section{Table-1: Demographic characteristics of the} participated students

\begin{tabular}{|c|c|}
\hline Variable & $\mathbf{N}(\mathbf{\%})$ \\
\hline Education Level & \\
\hline University & $162(48.5)$ \\
\hline High School & $172(51.5)$ \\
\hline Age & \\
\hline$\leq \mathbf{2 0}$ & $198(59.3)$ \\
\hline$\geq \mathbf{2 1}$ & $136(40.7)$ \\
\hline Nationality & \\
\hline Saudi & $302(90.4)$ \\
\hline Non-Saudi & $32(9.6)$ \\
\hline Social status & \\
\hline Single & $288(86.2)$ \\
\hline Married & $41(12.3)$ \\
\hline Divorced & $2(0.6)$ \\
\hline Engaged & $3(0.9)$ \\
\hline Living & \\
\hline Rural & $20(6)$ \\
\hline Urban & $314(94)$ \\
\hline
\end{tabular}

\section{Medications information sources}

More than half of the students considered physicians as the major utilized source of medications information and $95(28.4 \%)$ of them consulted pharmacists. However, about 56 (16.8\%) of them obtained their knowledge from mass media via the internet. Moreover, very few students gained information from (TV, newspapers, commercial advertising) (Figure 1). 


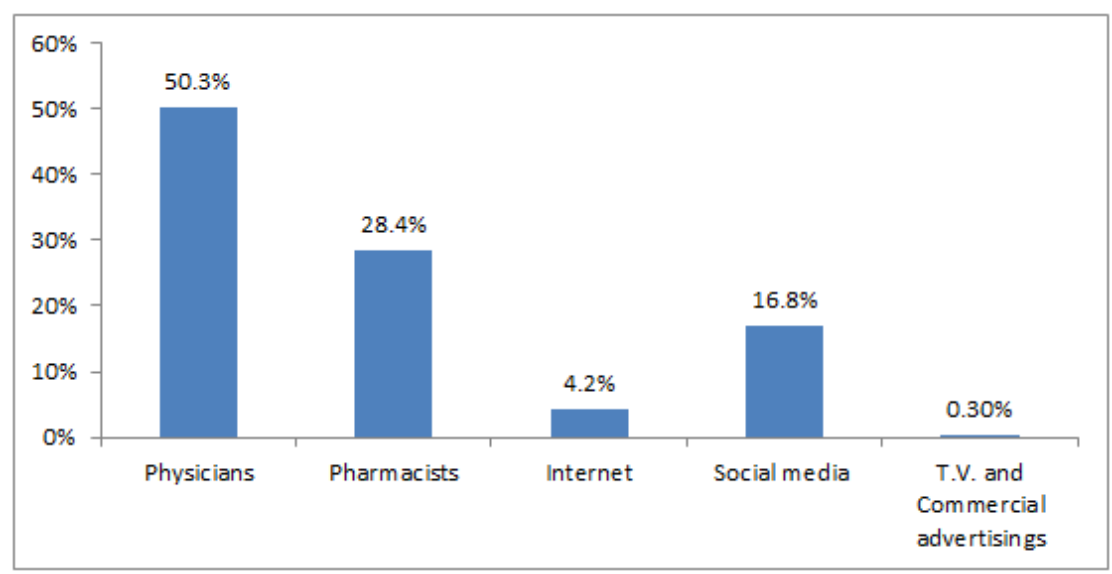

Fig-1: Medications information sources

\begin{abstract}
Assessment of Students' knowledge towards medications use

Most of the students appeared to have adequate knowledge and understanding about medication use. More than half of the students thought that they can differentiate between reliable and unreliable medication information resources. On the other hand, more than $40 \%$ of them preferred to use
\end{abstract}

medication without prescription (Table 2). The findings also showed that most of the students had better knowledge about the fact that overuse of medications is associated with side effects, but only $123(\approx 37 \%)$ of them knew that long-term use of some medicines may cause addiction. Table 2 also presented the responses on the questions designed to assess knowledge on medication use.

Table-2: Female Students General Knowledge towards Medications Use

\begin{tabular}{|l|c|c|c|}
\hline \multicolumn{2}{|c|}{ Question } & \multicolumn{2}{c|}{ N (\%) } \\
\cline { 2 - 4 } & Yes & No & Don't know \\
\hline $\begin{array}{l}\text { Differentiation between reliable and unreliable medications } \\
\text { information resources? }\end{array}$ & $199(59.6)$ & $107(32.0)$ & $28(8.4)$ \\
\hline Better to obtain medications with prescription during exams? & $170(51.0)$ & $135(40.4)$ & $29(8.6)$ \\
\hline Overuse of medications is associated with serious side effects? & $289(86.5)$ & $38(11.4)$ & $7(2.1)$ \\
\hline Long-term use of some medicines may cause addiction & $123(36.9)$ & $79(23.6)$ & $132(39.5)$ \\
\hline Analgesics are commonly used during exams & $271(81.1)$ & $63(18.9)$ & -- \\
\hline Stimulants are commonly used during exams & $88(26.4)$ & $169(50.6)$ & $77(23)$ \\
\hline $\begin{array}{l}\text { Traditional or Herbal medicines are natural and therefore safe, } \\
\text { without side effects }\end{array}$ & $209(62.6)$ & $80(24.0)$ & $45(13.4)$ \\
\hline $\begin{array}{l}\text { Gastrointestinal complaints were the top reported health } \\
\text { complaints during exams }\end{array}$ & $81(24.3)$ & $213(63.7)$ & $40(12)$ \\
\hline $\begin{array}{l}\text { Prevalence of menstrual changes is high among students during } \\
\text { exams }\end{array}$ & $276(82.7)$ & $56(16.7)$ & $2(0.6)$ \\
\hline
\end{tabular}

\section{The most common medications used in Exams}

The results in this section, was to explore and identify students' justification for use of medication during exams. Major symptoms experienced by students during exam period include headache, chest pain and respiratory problems, stomach and colon pain, anxiety, nervousness and sleep disturbances. The most common used medications among respondents were antihistamine medications, followed by analgesics (Panadol, Aspirin Ibuprofen and NASID) to relief headaches, fever and other pain due to menstruation. Other commonly used medications during exam period, in decreasing order of prevalence, were antibiotics, Flu and Cold medications, vitamins, antacids and CNS stimulants (Fig. 2). 


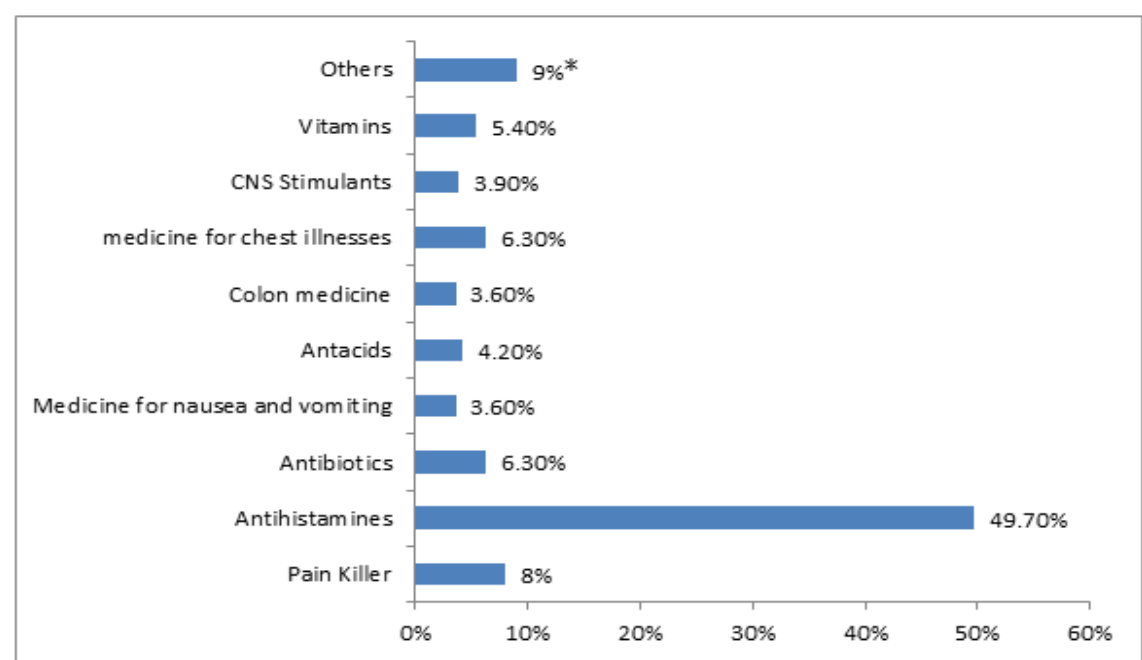

Fig-2: Medications used during Exams

*Medications recommended by friends.

\section{Attitude towards Medications' use}

Majority of the respondents didn't advice their friends to use medications according to their previous experiences. More than half of students disagreed with the claim that using medication during exams improves their performance, and most of them agree that exams affect their health status and food habits to a large degree. Nearly sixty percent read the medications labels' instructions before use. Table (3) showed participants' attitudes on medications use.

Table-3: shows the attitude assessment levels of respondents towards use of medicines

\begin{tabular}{|c|c|c|c|}
\hline \multirow[t]{2}{*}{ Question } & \multicolumn{3}{|c|}{$\mathbf{N}(\%)$} \\
\hline & Yes & No & Sometimes \\
\hline $\begin{array}{l}\text { Advising friends to use medications according to previous } \\
\text { experiences? }\end{array}$ & $53(15.9)$ & $241(72.2)$ & $40(12)$ \\
\hline Reading medication label instructions & 197(59) & $87(26)$ & $50(15)$ \\
\hline Using medication during exams improve academic performance & $50(15 \%)$ & $192(57.5 \%)$ & $92(27.5 \%)$ \\
\hline Side effects affect academic performance & $105(31.4 \%)$ & $151(45.2 \%)$ & $78(23.4 \%)$ \\
\hline Use medications with prescription & $\begin{array}{c}109 \\
(32.6 \%)\end{array}$ & $\begin{array}{c}135 \\
(40.4 \%)\end{array}$ & $\begin{array}{c}90 \\
(27 \%)\end{array}$ \\
\hline
\end{tabular}

\section{The impact of exams on students' health}

This section reflects the most common health problems experienced by students during exams period. Table 4 and Figures 3 and 4 showed that about 162 $(48.5 \%)$ of the female students agreed that exams affect their health status and food habits to a large degree. About $187(56 \%)$ of the respondents answered that exams caused anxiety to a large extent. Insomnia and sleep disturbances were two of the problems that were associated with anxiety according to the answers of 168
$(50.3 \%)$ of the participants in the questionnaires. Headache was the most arising health problem during exams with the $(44.3 \%)$ according to the answers of a large slice. They stated that this case was followed by stomach pain $(27.8 \%)$ and finally respiratory problems $(15.9 \%)$. About $94(28 \%)$ of the students found it difficult to concentrate during exams to a large extent and almost $100(30 \%)$ of them to a medium and small extent.

Table-4: The Impact of exams on the health of the Students and the most common health problems arises during exams period

\begin{tabular}{|l|c|c|c|c|}
\hline \multicolumn{1}{|c|}{ Status } & Large extent & Medium extent & Small extent & No effect \\
\hline Exams affect health status and food habits & 162 & 110 & 42 & 20 \\
\hline Feeling headache during exams & 148 & 86 & 59 & 41 \\
\hline Stomach pain and IBD & 93 & 62 & 89 & 90 \\
\hline Unable to concentrate during exams & 93 & 103 & 102 & 36 \\
\hline Chest pain\& respiratory issues & 53 & 45 & 61 & 175 \\
& $(15.9 \%)$ & $(13.5 \%)$ & $(18.3 \%)$ & $(52.4 \%)$ \\
\hline Causing anxiety & 187 & 107 & 29 & 11 \\
& $(56.0 \%)$ & $(32.0 \%)$ & $(8.7 \%)$ & $(3.3 \%)$ \\
\hline
\end{tabular}




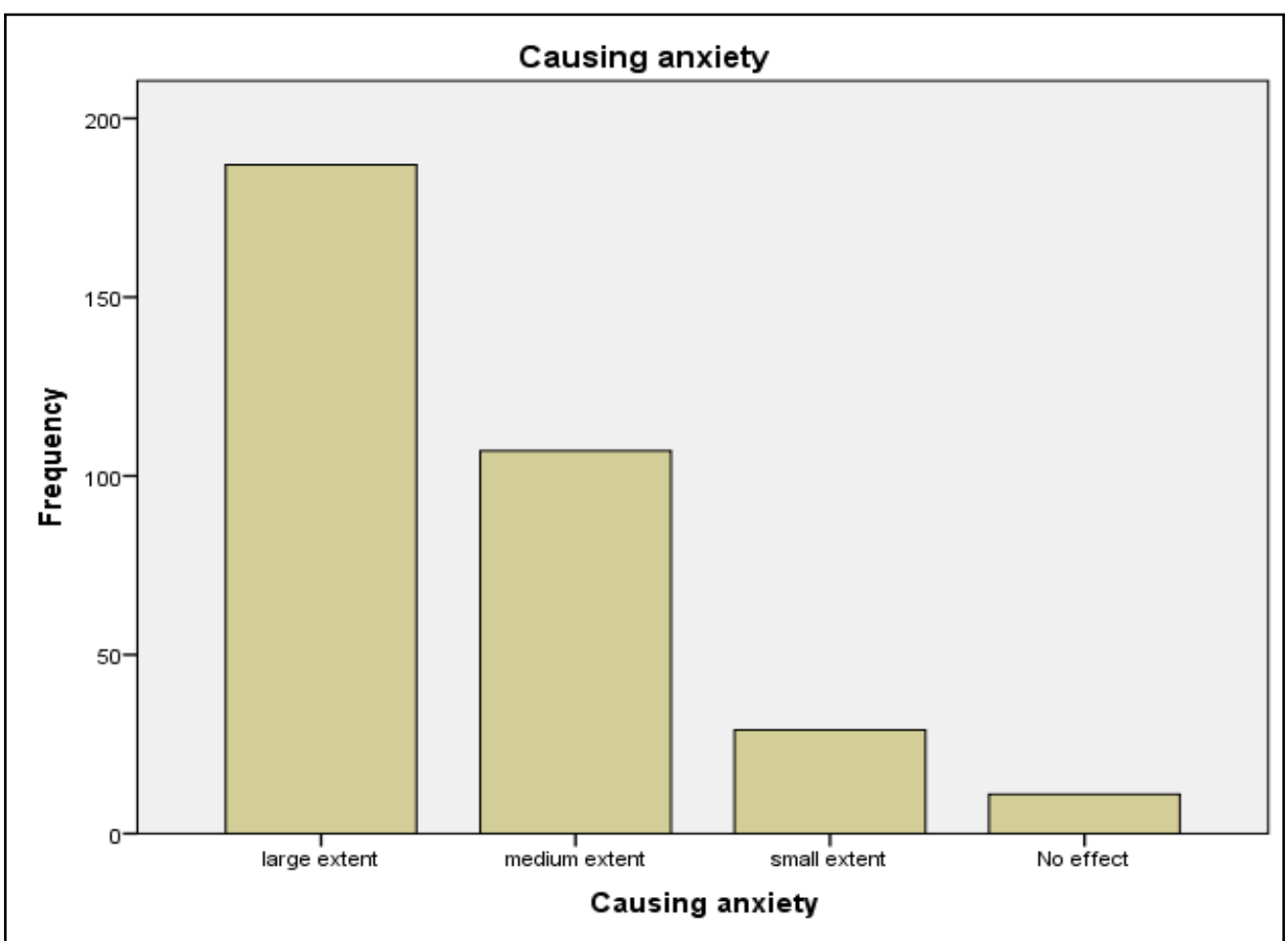

Fig-3: Anxiety associated with exams period

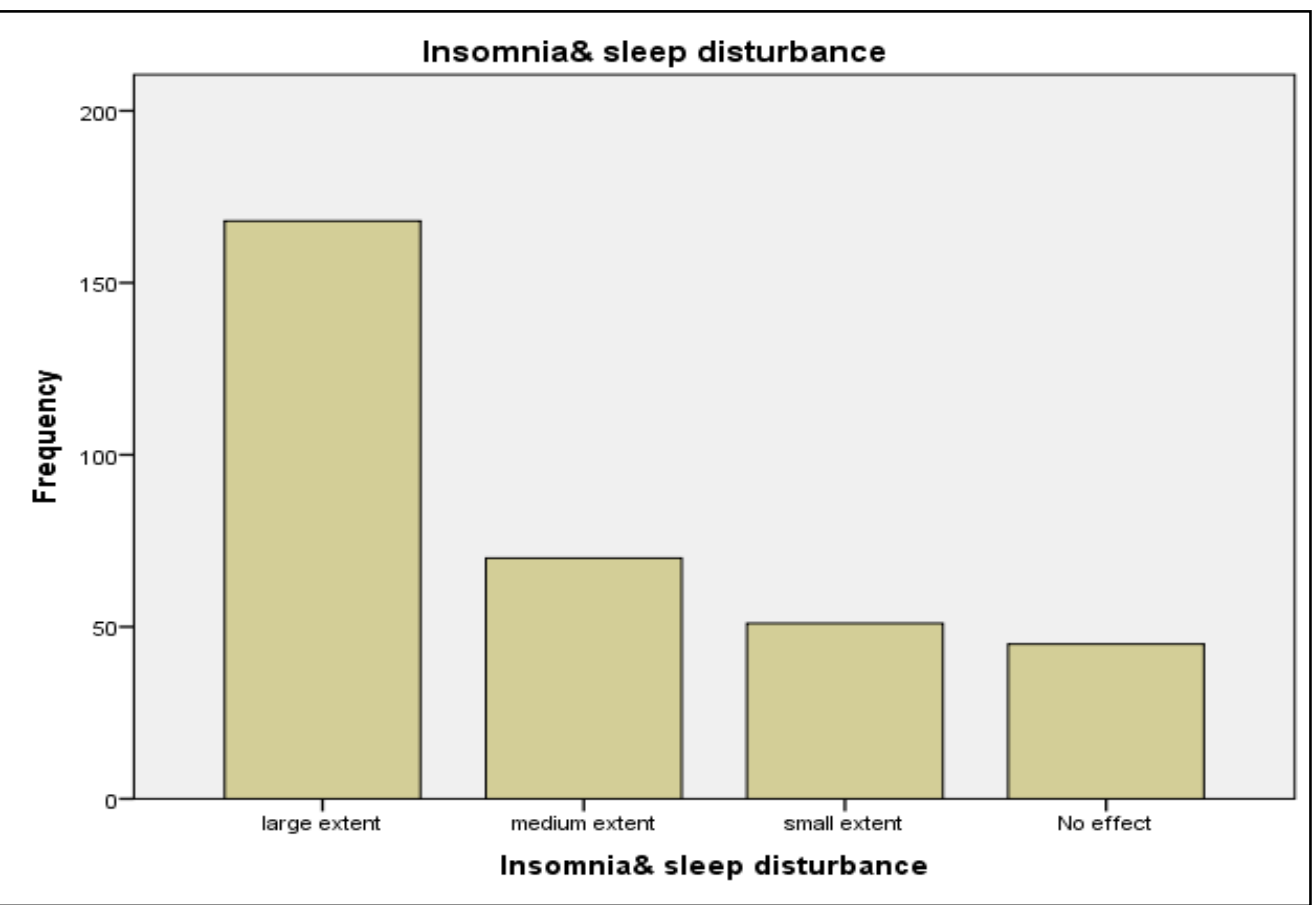

Fig-4: Exams causing insomnia and sleep disturbance

Use of Natural Alternative and Energy Drinks instead of Medication during exams

Most of the respondents preferred to use natural alternative and energy drinks than medication during exams; they preferred to substitute stimulants with coffee or tea. About half of them thought that consuming energy drinks increased during exams period, mainly due to the low cost of these energy drinks (Table 5). 
Table-5: Students' Preference between use of natural alternative or energy drinks and medication

\begin{tabular}{|c|c|c|c|c|}
\hline $\begin{array}{l}\text { Preferring natural alternative during } \\
\text { exams as tea and coffee }\end{array}$ & Frequency & Percent & Valid Percent & Cumulative Percent \\
\hline Yes & 241 & 72.2 & 72.2 & 72.2 \\
\hline No & 36 & 10.8 & 10.8 & 82.9 \\
\hline Sometimes & 57 & 17.1 & 17.1 & 100.0 \\
\hline Total & 334 & 100.0 & 100.0 & \\
\hline \multicolumn{5}{|l|}{ Consuming energy drinks during exams } \\
\hline Yes & 152 & 45.5 & 45.5 & 45.5 \\
\hline No & 84 & 25.1 & 25.1 & 70.7 \\
\hline Sometimes & 98 & 29.3 & 29.3 & 100.0 \\
\hline Total & 334 & 100.0 & 100.0 & \\
\hline \multicolumn{5}{|l|}{$\begin{array}{l}\text { Ease to get and use Low cost energy } \\
\text { drinks }\end{array}$} \\
\hline Yes & 139 & 41.6 & 41.6 & 41.6 \\
\hline No & 122 & 36.5 & 36.5 & 78.1 \\
\hline Sometimes & 73 & 21.9 & 21.9 & 100.0 \\
\hline Total & 334 & 100.0 & 100.0 & \\
\hline
\end{tabular}

The effect of Medication use during exams on the Academic Performance of female students

The study findings showed that only $50(15 \%)$ of the participated students agreed that using medications during exams may improve their performance. About 94 (28\%) of them believed that medications side effects may sometimes affect their academic performance. In addition, most of the rural female students believed that using medications during exams may improve their academic performance, compared to only $13 \%$ of urban students $(P=0.001)$. The result reflected attitude of the different cultures between city and village residence (Table 6).

Table-6: Relationship between Living and effect of medication use during exams on the academic performance

\begin{tabular}{|c|c|c|c|c|c|}
\hline \multirow{2}{*}{\multicolumn{2}{|c|}{$\begin{array}{l}\text { Living using drugs during exams } \\
\text { improve my performance }\end{array}$}} & \multicolumn{3}{|c|}{ Response } & \multirow[t]{2}{*}{ Total } \\
\hline & & Yes & No & Sometimes & \\
\hline \multirow[t]{2}{*}{ Living } & Rural & 10 & 7 & 3 & 20 \\
\hline & Urban & 40 & 185 & 89 & 314 \\
\hline \multicolumn{2}{|l|}{ Total } & $50(15 \%)$ & $192(57.5 \%)$ & $92(27.5 \%)$ & $334(100 \%)$ \\
\hline \multicolumn{2}{|c|}{ Chi-Square Tests } & Value & $\mathrm{df}$ & \multicolumn{2}{|c|}{ Asymp. Sig. (2-sided) } \\
\hline \multicolumn{2}{|c|}{ Pearson Chi-Square } & $20.525^{\mathrm{a}}$ & 2 & \multicolumn{2}{|c|}{.000} \\
\hline \multicolumn{2}{|c|}{ Likelihood Ratio } & 14.810 & 2 & \multicolumn{2}{|c|}{.001} \\
\hline \multicolumn{2}{|c|}{ Linear-by-Linear Association } & 11.728 & 1 & \multicolumn{2}{|c|}{.001} \\
\hline \multicolumn{2}{|c|}{$\mathrm{N}$ of Valid Cases } & 334 & & & \\
\hline
\end{tabular}

Role of Parents, Academic body and Pharmacists about use of medication during exams

Most of the students in the present study confirmed the role of their parents in supporting and preparing the convenient environment for them to reduce stress during exams, while almost 267 (80\%) of the students confirmed that their parents were aware of the drugs their children taking during exams. On the other hand, most of the students thought that the existence of a clinic/pharmacy in the school/college is important. From these findings, majority of the students confirmed the importance of school and university to organize awareness courses about health education and medication use during exams (Table 7). 
Badraddin M. Al-Hadiya et al., Saudi J Med Pharm Sci, September, 2020; 6(9): 594-604

Table-7: The Role of Parents, Education body (Schools/University) and Pharmacists in the of Medication during Exams

\begin{tabular}{|c|c|c|c|c|}
\hline Item & Frequency & Percent & $\begin{array}{l}\text { Valid } \\
\text { Percent }\end{array}$ & $\begin{array}{l}\text { Cumulati } \\
\text { ve Percent }\end{array}$ \\
\hline \multicolumn{5}{|c|}{$\begin{array}{l}\text { Parents support and prepare the convenient } \\
\text { environment to reduce stress during exams }\end{array}$} \\
\hline Yes & 285 & 85.3 & 85.3 & 85.3 \\
\hline No & 49 & 14.7 & 14.7 & 100.0 \\
\hline Total & 334 & 100.0 & 100.0 & \\
\hline \multicolumn{5}{|c|}{ Parents explain the consequences of misusing drugs } \\
\hline Yes & 226 & 67.7 & 67.7 & 67.7 \\
\hline No & 108 & 32.3 & 32.3 & 100.0 \\
\hline Total & 334 & 100.0 & 100.0 & \\
\hline \multicolumn{5}{|c|}{$\begin{array}{l}\text { Parents aware of the drugs their children take during } \\
\text { exams }\end{array}$} \\
\hline Yes & 267 & 79.9 & 79.9 & 79.9 \\
\hline No & 67 & 20.1 & 20.1 & 100.0 \\
\hline Total & 334 & 100.0 & 100.0 & \\
\hline \multicolumn{5}{|c|}{$\begin{array}{l}\text { Importance of the presence of school/university. } \\
\text { pharmacy/clinic }\end{array}$} \\
\hline Yes & 305 & 91.3 & 91.3 & 91.3 \\
\hline No & 29 & 8.7 & 8.7 & 100.0 \\
\hline Total & 334 & 100.0 & 100.0 & \\
\hline \multicolumn{5}{|c|}{ Importance of giving lectures about drugs education } \\
\hline Yes & 259 & 77.5 & 77.5 & 77.5 \\
\hline No & 75 & 22.5 & 22.5 & 100.0 \\
\hline Total & 334 & 100.0 & 100.0 & \\
\hline
\end{tabular}

Relationship between Education and knowing that Overuse associated with Side effects

University Female students have higher percentage of knowledge of the consequences of overuse of medications than those of high schools (Table 8)

Table-8: The relationship between education and Overuse of medication associated with Side effects

\begin{tabular}{|c|c|c|c|c|}
\hline \multirow{2}{*}{\multicolumn{2}{|c|}{$\begin{array}{l}\text { Education * knowing that } \\
\text { overuse associated with SE }\end{array}$}} & \multicolumn{2}{|c|}{$\begin{array}{l}\text { Knowing that overuse } \\
\text { associated with SE }\end{array}$} & \multirow[t]{2}{*}{ Total } \\
\hline & & Yes & No & \\
\hline \multirow[t]{2}{*}{ Education } & University & 146 & 16 & 162 \\
\hline & High School & 143 & 29 & 172 \\
\hline \multicolumn{2}{|l|}{ Total } & 289 & 45 & 334 \\
\hline
\end{tabular}

\section{DiscuSSION}

The main reason of deciding to perform this research study was to focus on the issue of the high prevalence of self-medication among high schools and university colleges' female students during exam periods. This urgent need to the medications during exams was for multiple reasons including the belief that it could help the students to improve their study performance.

To the best of the researchers' knowledge, the current study is considered the first comprehensive one about female (schools and university) students' use of medication during exams in Saudi Arabia. In addition, it showed the importance of the role of pharmacist, parents and education in this topic in Taif City. The major aim of this study was to assess schools and university female students' knowledge and attitude towards the use of medicines during exams in Taif City (KSA). The study also aimed to assess and compare rural to urban female students' knowledge and attitude on medication use during exams period.

The majority of participants in the present study were Saudis (94\%), with common socio-cultural and educational backgrounds. The study was conducted using randomized samples of university and high schools female students. Students in different university disciplines were included to avoid being biased, and the survey was carried out immediately after exams period in Taif City to obtain more accurate data from students about their attitude towards using medication during exams period. 
The study findings showed that half of the student's medical information resources about drugs came from physicians, followed by pharmacists. This indicates the less role of the pharmacist as an expert and knowledgeable in medication. Moreover, the pharmacist should play a key role in educating and informing people about the risks of self-care medication. The study also showed that more than third of the female students preferred to take medications without prescription and that confirmed their tendency for self-medication without referring or seeking any consultation. However, the majority agreed that overuse of medications during exams may be associated with side effects; only $37 \%$ agreed that long-term use of some medicines may cause addiction. The study confirmed that health education is in positive relationship with the knowledge that overuse of medication is associated with side effect.

The second aim for this study was to assess the impact of exams on the health of the students and what were the most common health problems, arising during exams period. It is not surprising that test situations evoke anxiety for many of students especially when considering the impact of tests on one's life in general, including the educational, vocational, emotional and other life aspects. Anxiety may involve many negative effects including poor performance, low motivation, negative self-evaluation beliefs, and low concentration, as well as an increase in school dropout rates and general anxiety. Insomnia and sleep disturbances are two of the problems that are connected with anxiety, as indicated by the $50.3 \%$ answers. Headache was the most arising health problem during exams with the 44.3 percent 'large extent' answers, followed by stomach pain $(27.8 \%)$ and finally respiratory problems $(15.9 \%)$. With all these impacts of the exams on the health only $27.8 \%$ of the students find difficult concentration during exams to a large extent and almost $30 \%$ to a medium and small extent. These investigated medical conditions led the students to self-medication during exams [12-16, 24-27].

It was found that only $15 \%$ of the participated students agreed that using medications during exams may improve their performance. In addition, most of the rural female students believe that using medications improve their academic performance. $(P=0.001$ and that is a result of the different culture between urban and rural living areas.

The most common used medications among high schools and university students were antihistamine medications, followed by analgesics. These results were similar with those obtained by researches done in some Arabian Gulf countries, such as Kuwait [38], UAE [39], while in Riyadh (KSA) [40] analgesics (NASID) in particular were the most used medications by students. A considerable percentage of participants preferred the use of energy drinks and alternatives (coffee and tea) as stimulants during exams period because of their availability, low cost and free from side effects.

Most of the students in the present study confirmed the role of their parents in supporting and preparing the convenient environment for them to reduce stress during exams and also confirmed that their parents were aware of the drugs their children took during exams. This is a very optimistic finding that indicates the high level of parents' keenness. Parents explain the consequences of misusing drugs. On the other hand, almost all the participants thought that the existence of a clinic/pharmacy in the school/college is important. From our findings, most of the students thought that it is important that the school and university should organize awareness courses about health education and medication use during exams. Although few of them disagreed, indicating either they were not aware about the importance of such courses, or they think that the education courses are boring and useless.

University Female students have better satisfactory knowledge of drug use and consequences of overuse of medications compared to those of high schools. This difference may be mainly due to higher level of education observed among the former group having better chances to come across considerable information about medication use and safety. Moreover, presence of healthcare center in the university provided better communication and education to the students to understand consequences of drug use and safety message readily.

\section{RESEARCH LIMITATIONS}

The present research work was only targeting enrolment female respondents. Due to community cultural norms, one of the major limitations was the refusal of a large number of female students to participate in the study. Therefore, similar studies to the current one, financially supported, are required by the enrolment of female students in all of the kingdom schools and universities to investigate the use of medicines during exams. No guidelines for health promotion were available in schools and universities to support us to perform more intensive work on the current study.

\section{CONCLUSION}

The present study findings confirmed the high prevalence of self-medication among high schools and university colleges' students during exams. Female students' age and educational institution were the main factors significantly affecting the use of medicines during exams. There was variation in the total knowledge on medications use between the respondents. A large percent of the students were taking 
medications during exams for multiple reasons. The most common health issues happened during exams was the lack of appetite, anxiety, insomnia and headache. Most common medications taken during exams by the students were: antihistamines, pain killers, antibiotics and stimulants sequentially. About half of the respondent students consulted doctors or pharmacists for information on drugs. The current study showed that most of the rural students were found to believe that using drugs during exams improved their performance unlike urban ones. Moreover, despite variable knowledge about medications use during exams, most of the students demonstrated positive attitudes regarding this use. They exhibited better awareness and willingness for organizing health educational programs and courses to contribute to their knowledge about medication use during exams. Those who disagreed may indicate either they were not aware about either how important, or they thought that these education courses were boring and useless. Parents can help in their role by supporting their daughters and teaching them the safest alternative ways to keep them focused and reduce the anxiety associated with the exams, e.g., preparing the quiet and healthy environment to help them study, keep the noise down, healthy diet. Etc.

National guideline on medicine access should be developed and strong measures should be implemented to halt the selling of medications without a proper prescription. In addition, health education intervention regarding the risks of inappropriate selfmedication is essential, and students should be educated on the consequences of self-medication practices.

\section{RECOMMENDATIONS}

1. Education for drug abuse prevention in schools may be defined as the educational programs, policies, procedures and other experiences that contribute to the achievement of broader health goals of preventing drug use and abuse.

2. Schools and colleges should change students' behavior and increase their awareness towards using medications by educating them about the safe use of medications and the serious consequences of the misuse and its impact on the overall health especially during exams period.

3. Upgrading student's knowledge and execution of educational programs about medication education in form of pictures, videos, brochures and lectures are effective. Also, to develop their life skills strategies to prepare them for challenging situations such as exams without turning to medications, are so effective.

4. Introduction of the use of medicines into the health education component of school curricula or into adult education programs, such as literacy courses.

5. Recruitment of female students from one city in Saudi Arabia limits the generalizability of the obtained results to the female students in the whole country. Future studies and recruitment of a large representative sample from the whole country are necessary in order to explore the public knowledge better. This will affect the attitudes and practices on medication use during exams.

\section{ACKNOWLEDGEMENTS}

The authors would like to thank the Pharm D female students (College of Pharmacy, Taif University, KSA) for their participation and the great effort done in data collection. Thanks and appreciations to Dr. Azhari Abdullah for his unconditional support and kind help and effort in the statistical part of this project. The authors also wish to thank Prof. Mirghani A. Yousif for his help in revising and editing this article

Disclosure: The authors declare that there is no conflict of interests regarding the publication of this paper. Funding or Source of Support: None. The study was not supported by any external or internal grant.

Ethical approval: Ethical approval for the conduction of the research was obtained from the Pharmacy Practice Research Unit (PPRU), College of Pharmacy, Taif University, Saudi Arabia.

\section{REFERENCES}

1. Farlex Partner Medical Dictionary. (2012). Medication.

2. Nancy, L. Rollins. (2011). Medication Administration Curriculum. Department of Health and Human Services. Section.

3. World Health Organization. (2007). The conceptual framework for the international classification for patient safety. Geneva, World Health Organization, World Alliance for Patient Safety.

4. Hsiao, F., Lee, J., Huang, W., Chen, S., \& Chen, H. (2006). Survey of medication knowledge and behaviors among college students in Taiwan. Am J Pharm Educ, 70(2), 1-7.

5. Prep, K.T. 9 harmful effects of test induced stress | Kaplan test prep. (2014). Available at: http://www.kaptest.com/blog/med-schoolpulse/2014/11/17/9-harmful-effects-test-inducedstress/ (Accessed: 15 November 2016).

6. Jack, N. (2012). Medical consequences of drug abuse. Available at:

https://www.drugabuse.gov/related-topics/medicalconsequences-drug-abuse (Accessed: 16 November 2016). 
7. Mehlman, M. J. (2006). Prescription drug abuse chart. National Institute on Drug Abuse; Washington, DC.

8. "Get the Facts" Prescription Drug Abuse on College Campuses (2010). National Counsel on Patient Information and Education.

9. Cooper, R.J. (2013). Over-the-counter medicine abuse-a review of the literature. Journal of Substance Use, 18(2): 82-107.

10. Chambers, C.T., Reid, G.J., McGrath, P.J., Finley, G.A. (1997). Self-administration of over-thecounter medication for pain among adolescents. National Library of Medicine, 151(5): 449-55.

11. The. (2011). European School Survey Project on Alcohol and other Drugs (ESPAD) Report: Substance use among students in 36 European countries. The European Monitoring Centre for Drugs and Drug Addiction (EMCDDA), 2012.

12. Elin, O. Rosvold. (2008). Self-reported use of medicines among university students in Oslo, Norwayyvind Palm. The Norwegian Journal of Epidemiology, 18(2): 195-199.

13. Abahussain, E., Matowe, L. K., \& Nicholls, P. J. (2005). Self-reported medication use among adolescents in Kuwait. Medical principles and practice, 14(3), 161-164.

14. Klemenc-Ketis, Z., Hladnik, Z., \& Kersnik, J. (2010). Self-medication among healthcare and nonhealthcare students at University of Ljubljana, Slovenia. Medical Principles and practice, 19(5), 395-401.

15. Gelayee, D. A. (2017). Self-medication pattern among social Science University students in Northwest Ethiopia. Journal of pharmaceutics, 2017.

16. Almalak, H., Alkhelb, D. A., Alsaleh, H. M., Khan, T. M., Hassali, M. A. A., \& Aljadhey, H. (2014). Students' attitude toward use of over the counter medicines during exams in Saudi Arabia. Saudi Pharmaceutical Journal, 22(2), 107-112.

17. Botvin, G. (1997). Preventing drug use among children and adolescents. Second edition. National Institute of Drug Abuse (Weill Cornell Medical College, Institute of Prevention Research, U.S. Department of Health and Human Services. United States of America).
18. Wilson, B. (1998). Quality Education and the Health of Young Australians, HIV/AIDS and Sexual Health and Drug Education Forums (Education Queensland, Health Issues Section, Australia).

19. Pigg, R. (1989). The contribution of school health programs to the broader goal of public health: The American experience. Journal of School Health, 59(1), 25-30.

20. Resnicow, K., Allensworth, D. (1996). Conducting a comprehensive school health program. Journal of School Health, 66(2), 59-63.

21. Moon, A., Mullee, M., Rogers, L., Thompson, R., Speller, V., \& Roderick, P. (1999). "Helping schools become health promoting: An evaluation of the Wessex Healthy Schools Award." Health Promotion International, 14: 111-122.

22. Stewart-Brown, S. (2006). "What is the evidence on school health promotion in improving school health or preventing disease and specifically what is the effectiveness of the health promoting schools approach?" Copenhagen: World Health Organization.

23. Laing, R., Hogerzeil, H.V., Ross-Degnan, D. (2001). Ten Recommendations to Improve the Use of Medicines in Developing Countries. Health Policy and Planning, 16(1):13-20.

24. Greely, H., Sahakian, B., Harris, J., Kessler, R. C., Gazzaniga, M., Campbell, P., \& Farah, M. J. (2008). Towards responsible use of cognitiveenhancing drugs by the healthy. Nature, 456(7223), 702-705.

25. Farah, M. J., Illes, J., Cook-Deegan, R., Gardner, H., Kandel, E., King, P., \& Wolpe, P. R. (2004). Neurocognitive enhancement: what can we do and what should we do?.Nature reviews neuroscience, 5(5), 421-425.

26. Goodman, R. (2010). Cognitive enhancement, cheating, and accomplishment. Kennedy Institute of Ethics Journal, 20(2), 145-160.

27. Kumar, A., \& Vandana, A. N. A. (2016). Analgesics self-medication and its association with sleep quality among medical undergraduates. Journal of Clinical and Diagnostic Research: JCDR, 10(12), FC07. 